\title{
The feasibility and cost of a large multicentre audit of process and outcome of prostatectomy
} Mark Emberton, David E Neal, Nick Black, Mark Harrison, Mark Fordham,
Michael P McBrien, Robert E Williams, Klim McPherson, H Brendan Devlin
Surgical Audit Unit, Royal College of Surgeons of England, London WC2A 3PN

Mark Emberton, research fellow

H Brendan Devlin, director

University of Newcastle upon Tyne, Newcastle upon Tyne David E Neal, professor of surgery

London School of Hygiene and Tropical Medicine,

London

Nick Black, professor of health services research Klim McPherson,

professor of public health epidemiology

Royal Hampshire County Hospital, Winchester

Mark Harrison, consultant urologist

Royal Liverpool

Hospital,

Liverpool

Mark Fordham,

consultant urologist

West Suffolk Hospital,

Bury St Edmunds

Michael P McBrien,

consultant surgeon

General Infirmary,

Leeds

Robert E Williams,

consultant urologist

Correspondence to:

Mr Emberton

Accepted for publication 24 July 1995

\begin{abstract}
Objective-To determine the feasibility of performing multicentre process and outcome audits of common interventions taking prostatic procedures as an example.

Design-Prospective, cohort study.

Setting-All National Health Service and independent hospitals in Northern, Wessex, Mersey, and South West Thames health regions.

Patients-5361 men undergoing prostatectomy identified by 103 of the 107 urologists and general surgeons performing prostatectomy in the study regions.

Main measures-Rates of participation by surgeons and patients; completeness of clinical data provided by surgeons; patient response rate and completeness of patient derived data; and cost.

Results-Most surgeons $(103,96 \%)$ agreed to participate. Overall, the proportion of eligible patients invited to take part was high $(89 \%)$, although this was only measured in South West Thames, where dedicated data collectors were employed. Few men $(80,1.5 \%)$ declined to participate. Of those surviving for three months after surgery, $82 \cdot 4 \% \quad(4226)$ completed and returned the postal questionnaire. The response rate was higher in South West Thames $(86.7 \%)$ than in the other regions $(80 \cdot 6 \%-80 \cdot 8 \%)$. The audit was well received: $91 \%$ of patients found the questionnaire easy to complete and only $2 \cdot 3 \%$ of them disapproved. Completeness of data was high with both the hospital and patient questionnaires. Missing data occurred in less than $5 \%$ of responses to most questions. The attributable cost was $£ 34.50$ per patient identified or $£ 44$ for patients in whom either the treatment outcome or vital status was known three months after their prostatectomy.

Conclusions-This multicentre audit of process and outcome of prostatectomy proved feasible in terms of surgeon participation, patient identification, and the quantity and quality of data collection. Whether the cost was warranted will depend on how surgeons use the audit data to modify their practice.

(Quality in Health Care 1995;4:256-262)
\end{abstract}

Keywords: multicentre outcome audit, feasibility, cost, prostatectomy.

\section{Introduction}

With a growing body of research evidence on the effectiveness and appropriateness of prostatectomy, ${ }^{1-17}$ there is a need for a parallel development in auditing the use of the procedure. There is a limit to the value that individual surgeons can gain from auditing their own work in isolation. Much can be gained by comparison with other providers, but for this to be meaningful it is essential that both case mix and outcome are measured in the same way. ${ }^{18-20}$ Such comparative audit needs to be arranged on a large multicentre basis. However, the feasibility of such an undertaking is unknown. Will clinicians agree to participate? Can accurate and complete data be collected when numerous hospitals are included? And what resources are required both centrally and locally?

With this background, the Royal College of Surgeons of England, through its surgical epidemiology and audit unit carried out a multicentre audit of the structure, process, and patient perceived outcome of all prostatectomies performed in four health regions in both the public and private sectors over six months. The principal objectives were to determine the feasibility of performing a multicentre audit; to describe the extent of variations in clinical practice; to describe patients' perceptions of their symptoms and quality of life before and after surgery; to compare individual surgeons' performance in terms of patient selection, clinical management, and outcome; and to explore the factors associated with mortality, morbidity, and patient perceived outcome.

We report on the first objective in this paper. Feasibility was judged on the following criteria: the rates of participation by surgeons and patients; the completeness of the clinical data provided by surgeons; the impact of using data collectors; patients' response rate and the completeness of data provided by patients; and the cost of carrying out the audit.

\section{Patients and methods}

SURGEONS

All surgeons performing prostatic procedures in the 56 National Health Service (NHS) acute hospitals in Mersey (10), Wessex (11), Northern (17), and South West Thames regions (18) were contacted by letter. The invitation to participate came from the chairman of the steering group and was countersigned by the relevant regional coordinator. Failure to reply was followed up by the regional coordinator. One meeting was 
held in each of the regions to explain the aim and objectives of the audit.

STUDY DESIGN

Data collection took place from 1 June to 30 November 1992 except in South West Thames, where collection occurred between September 1992 and February 1993. Recruitment of patients undergoing a prostatic procedure occurred at the time of surgery. The patient recruitment rate was assessed in South West Thames by visiting all hospitals (NHS and private sector) and comparing returns with theatre records.

A local data coordinator was appointed at each hospital site. This person was responsible for collecting the hospital questionnaires (see below) containing the patients' demographic and clinical data. The data coordinators were either audit assistants (91\%) or medical secretaries $(9 \%)$. Participating surgeons were asked to complete questionnaires on men who had undergone a prostatic operation while under their nominal care, irrespective of who was the principal operator.

The hospital questionnaires were returned in prepaid envelopes to the surgical audit unit. On receipt, an identifying number was sequentially allocated to guarantee continued confidentiality. Demographic data were entered on to a secure database ( $Q$ and $A$, Symantec) with the unique number as sole identifier. Thus any written link between demographic and clinical data was destroyed.

The local data coordinator ensured that every patient received a printed sheet after his operation that explained the nature of the study and invited participation. Three months later a patient questionnaire was sent to the patient's home with a covering letter and prepaid return envelope addressed to the surgical audit unit. Non-responders were sent a reminder two weeks later and, if that had no effect, a second reminder was sent after a further four weeks.

All patients were flagged at the NHS Central Registry, and the surgical epidemiology and audit unit was informed of any deaths. In this way the true response rate to the patient questionnaire could be obtained.

DEVELOPMENT OF HOSPITAL QUESTIONNAIRE The hospital questionnaire was designed using optical image scanning technology to permit fast, accurate, and confidential automated data entry through a sheet-fed scanner on to a computerised database. ${ }^{21} 22$ The principal operating surgeon was the person responsible for completing the questionnaire. As patients were recruited at the time of surgery, questions on the preoperative phase were completed retrospectively unlike postoperative data, which were collected prospectively. The variables in the hospital questionnaire included: mode and category of admission, preoperative investigations, physical health status as expressed by the American Society of Anaesthesiology (ASA) grade, operation and anaesthetic details, intraoperative and postoperative complications, and mode of discharge.
DEVELOPMENT OF PATIENT QUESTIONNAIRE During February 1992, 30 consecutive patients who had undergone prostatectomy three months previously were interviewed about their major likes and dislikes with respect to their recent hospital stay. Patients were then asked to complete a draft questionnaire which contained questions on symptoms, impact on lifestyle, sexual function, type and utility of information received, and satisfaction with care. Finally, we assessed the degree to which the questionnaire covered views and concerns about the hospital, the experience of the operation, and the outcome. The mean interview time was 42 minutes (range 30-95 minutes).

A pilot questionnaire was then formulated which included the American Urological Associations symptom index ${ }^{23} 24$ and an index of symptom bother which assessed how troublesome the symptoms were thought to be. Additional questions addressed both disease specific and generic quality of life ${ }^{25} 26$; sexual function (seven questions); information offered to patients before and after admission to hospital (10 questions); and the experience of the patient after discharge in terms of complications, visits to their general practitioner, and hospital readmissions. Finally, patients were given the opportunity to write freely about their overall experience.

ESTIMATION OF COST OF AUDIT

An estimation of the cost of the audit included the time consultant surgeons and trainees devoted to completing the questionnaire (estimated to take 15 minutes); the cost of coordination, analysis, and reporting carried out by the research fellow (ME); the cost of consumables, in particular for printing and posting questionnaires, for flagging patient records at the NHS Central Registry, and for equipment costs. Fixed overhead costs of the buildings were not accounted for as these were deemed to be negligible.

\section{STATISTICAL ANALYSIS}

The participation rates of surgeons and patients were calculated. The impact of dedicated data collectors in South West Thames region was explored by comparison of rates with other regions. The completeness of data derived from the two questionnaires was described for each question. Association between patient demographic characteristics and both the amount of difficulty experienced completing the questionnaire and the amount/ number of missing data were examined. Analyses of proportions were tested with the $\chi^{2}$ statistic. The comparison of means in relation to sociodemographic characteristics and missing values was performed using one way analysis of variance. Missing values in excess of $5 \%$ were declared. Calculations were performed on valid cases only (responses).

\section{Results}

PARTICIPATION RATES BY SURGEONS

One hundred and ten surgeons were identified in the four regions (Wessex, 24; Mersey, 25; Northern, 29; South West Thames, 32). Three 
surgeons chose not to take part: one said he was too busy; another would only participate if local funding was made available; and a third was approaching retirement. Six surgeons who agreed to take part subsequently failed to submit any patients. Of these, only one had performed any prostatectomies. Thus, of the 107 surgeons performing prostatectomy, $103(96 \%)$ were successfully recruited into the study. Two consultants retired during the audit and their successors agreed to take part.

There was a wide range of surgeons in terms of the numbers of men they operated on each year. During the six month period the mean number recruited to the audit was 51.3 (range 1-182). Twelve surgeons submitted fewer than 10 cases during the study period; in contrast, 28 submitted more than 75 cases. Most operations were performed by specialist (1516; $29.8 \%$ ) or generalist urological firms (2227; $43 \cdot 7 \%$ ). General surgeons accounted for only $934(18 \%)$ cases, in which 787 operations were performed by surgeons with a predominantly urological workload. The regions were similar in terms of the proportions of patients operated on by surgeons with different degrees of specialisation.

\section{RECRUITMENT OF PATIENTS}

The proportion of eligible patients recruited was assessed in South West Thames region, where it was $89 \cdot 4 \%$. Three quarters of surgeons invited over $90 \%$ of their patients to participate (fig). Although recruitment was not studied in the three other regions, any consultant firm identifying fewer than 10 patients during the study period was asked to confirm their operating record during the study. Overall, 5361 men were invited to participate, of whom $5281(98 \cdot 5 \%)$ agreed and 80 refused (table 1 ).

PATIENT RESPONSE

Patient questionnaires were sent to all 5281 men agreeing to participate unless it was known that the man had died. In all, 103(2\%) of the dispatched questionnaires were returned by the post office as incorrectly addressed or because the occupant had moved. Table 1 shows the number of completed questionnaires returned $(4226(82 \cdot 4 \%))$. A further 153

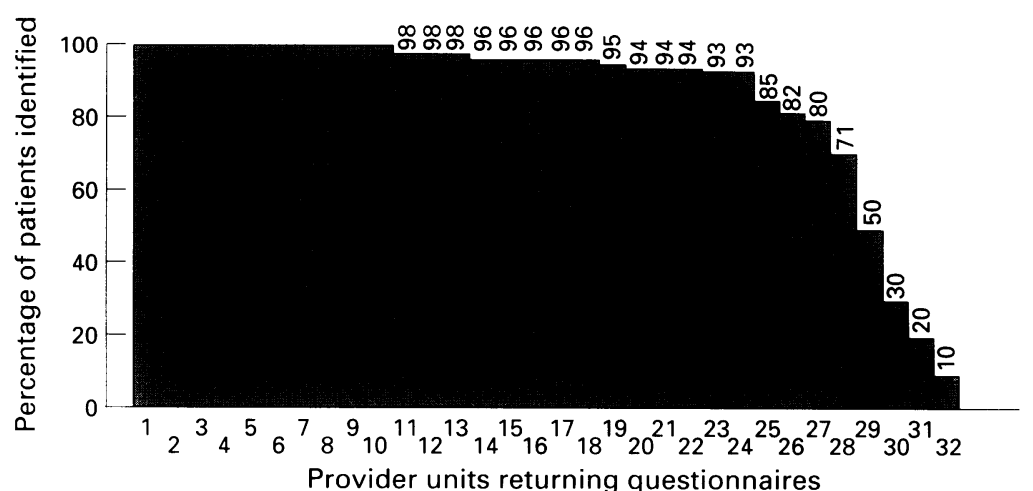

Proportions of patients from 23 provider units in South West Thames region invited to participate $(89.4 \%$ of operations were identified) questionnaires were returned unanswered, most often because of infirmity or poor memory. When these and the number of questionnaires returned by the post office were taken into account the response rate by men who received their questionnaire and were fit enough to complete it was $87 \%$.

Rates of return for completed patient questionnaires were similar in regions using the same method of data collection: Wessex $(80.6 \%)$, Mersey $(80.8 \%)$, and Northern $(80 \cdot 1 \%)$. In contrast, South West Thames, which had two full time dedicated data collectors during the period of the study, achieved a significantly higher return rate of $86.7 \%\left(\chi^{2}=37 \cdot 4, p<0.001\right)$.

COMPLETENESS OF HOSPITAL QUESTIONNAIRES No two hospitals collected data in quite the same way - complex methods that worked efficiently in one hospital were not applicable elsewhere. In 4981 out of $5094(97 \cdot 8 \%$ ) cases the patient's hospital notes were available to the doctor completing the questionnaire (it was unknown whether the notes were available for the other 321 cases). Consultants completed questionnaires for $2733(53.7 \%)$ cases, the remainder being done by senior registrars (619; $12.2 \%)$, registrars $(492 ; 9 \cdot 7 \%)$, and senior house officers or house officers $(879 ; 17.3 \%)$. The proportion of questionnaires which were completed by a consultant varied between health regions from $42 \cdot 5 \%$ to $70 \cdot 7 \%\left(\chi^{2}=\right.$ $182 \cdot 9, \mathrm{p}=0.0001)$. Only $235(5 \%)$ respondents reported any difficulty in completing the questionnaire.

The proportion of missing answers to a particular question was low for most questions $(0 \cdot 8 \%-2 \cdot 6 \%)$. Those missed in more than $5 \%$ of questionnaires were: whether the patient was treated under the NHS or privately, $8.6 \%$; duration of operation, $9.6 \%$; whether the patient was admitted to an intensive care unit, $8 \%$; and anticipated outcome (surgeon defined), $5 \cdot 7 \%$.

COMPLETENESS OF PATIENT QUESTIONNAIRES In the month before the operation, $514(13 \%)$ men had a catheter in place and therefore did not complete questions contributing to the preoperative American Urological Association's symptom and bother indices. Similarly, $86(2 \cdot 1 \%)$ men who had a catheter in place during the third postoperative month were not asked to report their postoperative symptoms.

Table 2 summarises the proportions of missing answers for each subject included. The only subjects in the preoperative phase in which more than $5 \%$ of respondents failed to answer were presence of a urinary catheter $(7 \cdot 9 \%)$, activity impairment $(5 \cdot 4 \%-6 \cdot 4 \%)$, and psychological impairment $(5 \cdot 2 \%-5 \cdot 7 \%)$. The utility of information received, decision making and quality of information during admission all had missing answers greater than $5 \%$. Answers to questions about postoperative health were more complete - the exceptions were questions addressing sexual function, in particular the question asking about change in ejaculatory characteristics $(32 \%)$. 
Table 1 Summary table showing identification, recruitment, and response rate of patients for participating regions and overall

\begin{tabular}{lcccccc}
\hline Region & $\begin{array}{l}\text { No of consultant } \\
\text { firms identified }\end{array}$ & $\begin{array}{l}\text { No that recruited } \\
\text { patients }\end{array}$ & $\begin{array}{l}\text { No of patients } \\
\text { invited to } \\
\text { participate }\end{array}$ & $\begin{array}{l}\text { No agreeing } \\
\text { to participate }\end{array}$ & $\begin{array}{l}\text { No (\%) surviving } \\
\text { three months }\end{array}$ & $\begin{array}{l}\text { No (\%) of completed } \\
\text { patient questionnaires }\end{array}$ \\
\hline Wessex & 24 & 23 & 1749 & 1714 & $1673(97 \cdot 6)$ & $1348(80 \cdot 6)$ \\
Mersey & 24 & 19 & 767 & 758 & $731(96 \cdot 4)$ & $\begin{array}{r}591(80 \cdot 8) \\
833(80 \cdot 1)\end{array}$ \\
Northern & 30 & 27 & 1104 & 1070 & $1040(97 \cdot 2)$ & $1505(97 \cdot 0)$ \\
South West Thames & 32 & 32 & 1552 & 1552 & $405(86 \cdot 7)$ \\
\hline Subtotal & 110 & 101 & 5172 & 5094 & $4949(97 \cdot 2)$ & $4077(82 \cdot 1)$ \\
\hline Trent* & 2 & 2 & 189 & 187 & $182(97 \cdot 3)$ & $149(81 \cdot 9)$ \\
\hline Total & 112 & 103 & 5361 & $5281(100)$ & $5131(97 \cdot 1)$ & $4226(82 \cdot 4)$ \\
\hline
\end{tabular}

*One hospital in Trent acted as a site for testing validity and reliability of data collection.

Half the respondents took the opportunity to provide free text information on any difficulties they had answering the questionnaire. Table 3 indicates that patients most frequently cited the questions on preoperative

Table 2 Proportions of missing responses by type of question in patient questionnaire

\begin{tabular}{|c|c|c|}
\hline Subject & $\begin{array}{l}\text { No of questions } \\
\text { on subject }\end{array}$ & $\begin{array}{l}\text { No (\%) of respondents } \\
\text { with no answer }\end{array}$ \\
\hline \multicolumn{3}{|c|}{ Preoperative phase (recollected) } \\
\hline Presence of catheter (month before operation) & 1 & $335(7 \cdot 9)$ \\
\hline Preoperative symptoms (AUA index) & 7 & $43(1 \cdot 3)$ to $104(3 \cdot 1)$ \\
\hline Incontinence & 1 & $42(1 \cdot 2)$ \\
\hline Symptom impact (level of bother) & 7 & $106(3 \cdot 1)$ to $112(3 \cdot 3)$ \\
\hline Disease specific impairment & 3 & $156(3 \cdot 7)$ to $176(4 \cdot 2)$ \\
\hline Global impairment & 3 & $151(3 \cdot 6)$ to $168(4 \cdot 0)$ \\
\hline Global satisfaction & 1 & $167(4 \cdot 0)$ \\
\hline Activity impairment & 3 & $230(5 \cdot 4)$ to $270(6 \cdot 4)$ \\
\hline Psychological impairment & 4 & $221(5 \cdot 2)$ to $239(5 \cdot 7)$ \\
\hline Physical functioning & 3 & $158(3 \cdot 7)$ to $193(4 \cdot 6)$ \\
\hline \multicolumn{3}{|c|}{ Information } \\
\hline Informed persistent symptoms & 1 & $103(2 \cdot 4)$ \\
\hline Informed retrograde ejaculation & 1 & $155(3 \cdot 7)$ \\
\hline Information utility & 3 & $234(5 \cdot 5)$ to $298(7 \cdot 0)$ \\
\hline Decision to undergo surgery & 1 & $233(5 \cdot 5)$ \\
\hline Global information quality & 1 & $225(5 \cdot 3)$ \\
\hline \multicolumn{3}{|c|}{ Postoperative phase (contemporaneous) } \\
\hline Presence of catheter & 1 & $188(4 \cdot 4)$ \\
\hline Postoperative symptoms (AUA index) & 7 & $50(1 \cdot 3)$ to $83(2 \cdot 1)$ \\
\hline Incontinence & 1 & $50(1 \cdot 3)$ \\
\hline Symptom impact (level of bother) & 7 & $124(3 \cdot 1)$ to $138(3 \cdot 5)$ \\
\hline Disease specific impairment & & $142(3 \cdot 4)$ to $148(3 \cdot 5)$ \\
\hline Global impairment & 3 & $135(3 \cdot 2)$ to $147(3 \cdot 5)$ \\
\hline Global satisfaction & 1 & $116(2 \cdot 7)$ \\
\hline Activity impairment & 3 & $111(2 \cdot 6)$ to $177(4 \cdot 2)$ \\
\hline Psychological impairment & 4 & $132(3 \cdot 1)$ to $146(3 \cdot 5)$ \\
\hline Physical functioning & 3 & $139(3 \cdot 3)$ to $142(3 \cdot 4)$ \\
\hline \multicolumn{3}{|c|}{ Complications after discharge } \\
\hline Disease specific complications & 6 & $98(2 \cdot 3)$ to $114(2 \cdot 7)$ \\
\hline \multicolumn{3}{|c|}{ Sexual impairment } \\
\hline Sexual activity before and after operation & 2 & $281(6 \cdot 6)$ to $293(6 \cdot 9)$ \\
\hline Ejaculatory characteristics & 4 & $\begin{array}{l}657(15 \cdot 5) \text { to } \\
1354(32)\end{array}$ \\
\hline Worry attributed to impairment & 1 & $554(12 \cdot 9)$ \\
\hline \multicolumn{3}{|c|}{ Sociodemographic characteristics } \\
\hline Cohabitation & 1 & $84(2)$ \\
\hline Completion full time education & 1 & $146(3 \cdot 5)$ \\
\hline Age by half decade & 1 & $66(1 \cdot 6)$ \\
\hline Social class by employment & 1 & $330(7 \cdot 8)$ \\
\hline Ethnic origin & 1 & $90(2 \cdot 1)$ \\
\hline Ease of questionnaire completion & 1 & $105(2 \cdot 5)$ \\
\hline Satisfaction with study participation & 1 & $94(2 \cdot 2)$ \\
\hline
\end{tabular}

AUA $=$ American Urological Association.

Table 3 Patients' reported difficulty in free text responses in answering particular questions in patient questionnaire ${ }^{\star}$

\begin{tabular}{lccc}
\hline Declared difficulty with questions & No of patients & $\begin{array}{l}\text { Proportion (\%) } \\
\text { of responders } \\
(n=4226)\end{array}$ & $\begin{array}{l}\text { Proportion (\%) by } \\
\text { type of question } \\
(n=1070)\end{array}$ \\
\hline Questions on sexual function & 486 & 11.5 & 45.4 \\
Several question types & 147 & 3.5 & 13.7 \\
Concept of bladder fullness & 131 & 3.1 & 12.2 \\
Recollection of pre-operative status & 87 & $2 \cdot 1$ & $8 \cdot 1$ \\
Questions on information & 85 & $2 \cdot 0$ & $7 \cdot 9$ \\
Quality of life questions & 69 & 1.6 & 6.4 \\
Postoperative complications & 65 & 1.5 & 6.1
\end{tabular}

*Overall, 911 patients made 1070 relevant comments on difficulty with questions. and postoperative sexual function as most difficult.

Most men (3776(89\%)) found the questionnaire either "very easy" (41\%) or "quite easy" (48\%) to complete. With advancing age, the proportion of men expressing difficulty increased: $6 \%$ of men under 65 expressed difficulty in contrast to $12 \%$ of men over 75 $\left(\chi^{2}=63 \cdot 6, p=0 \cdot 0001\right)$. Age of leaving full time education was not associated with difficulty in completing the questionnaire, but it was related to the patients' expressed approval of postal surveys of this type $\left(\chi^{2}=43 \cdot 3\right.$, $\mathrm{p}<0.0001)$. Socioeconomic class, defined by last full time employment, was associated both with men's understanding $\left(\chi^{2}=32 \cdot 1\right.$, $p=0.0001)$ and acceptance of the questionnaire $\left(\chi^{2}=78 \cdot 1, \mathrm{p}<0.0001\right)$ (table 4$)$.

Given that patients' perception of both difficulty and acceptability of the questionnaire was dependent on some sociodemographic variables, it was necessary to see whether the same variables were associated, in terms of degree and direction, with the quality of response. The missing values (mean) from the constituent questions to the preoperative American Urological Association's symptom index score (seven questions, each with six values) were calculated (table 5). Younger age, lower social class, and a shorter period of full time education were associated with significantly more missing values for the constituent questions, but the differences were small. Men who lived alone (and thus less likely to receive help with the questionnaire) did not differ significantly from those who cohabited. As almost all $(99 \%)$ respondents were white it was impossible to comment on the effect of ethnic group on completion of the questionnaire.

ESTIMATION OF COSTS

The direct costs of the audit are shown in table 6 . The principal expenditure was on project and clinical staff time. The cost of the study per patient identified $(n=5361)$ was $£ 34.50$ and per patient in whom outcome data were available $(n=4226)$ was $£ 44.00$. The cost of obtaining information on the vital status of non-responders $(n=955)$ through the NHS registry was $£ 26000$, or $£ 27.00$ per patient.

\section{Discussion}

The feasibility of auditing the outcome of a common surgical procedure was determined in 
Table 4 Patients'views of patient questionnaire by social class. Values are numbers (percentages) of patients

\begin{tabular}{lccccc}
\hline & \multicolumn{3}{c}{ Social class by last full time employment } & \multirow{2}{*}{ Total } \\
\cline { 2 - 5 } & Not specified & $A / B$ & $C 1 / C 2$ & $D / E$ & \\
\hline Ease of completion? & & & & & \\
Very easy & $109(32 \cdot 7)$ & $436(47 \cdot 4)$ & $927(41 \cdot 9)$ & $263(34 \cdot 6)$ & $1735(41 \cdot 1)$ \\
Quite easy & $128(38 \cdot 4)$ & $417(45 \cdot 4)$ & $1088(49 \cdot 2)$ & $408(53 \cdot 6)$ & $2041(48 \cdot 3)$ \\
Quite difficult & $17(5 \cdot 1)$ & $56(6 \cdot 1)$ & $147(6 \cdot 6)$ & $64(8 \cdot 4)$ & $284(6 \cdot 7)$ \\
Very difficult & $11(3 \cdot 3)$ & $4(0 \cdot 4)$ & $25(1 \cdot 1)$ & $17(2 \cdot 2)$ & $57(1 \cdot 3)$ \\
Missing values & $68(20 \cdot 4)$ & $6(0 \cdot 7)$ & $26(1 \cdot 2)$ & $9(1 \cdot 2)$ & $109(2 \cdot 6)$ \\
\hline Total & $333(100 \cdot 0)$ & $919(100 \cdot 0)$ & $2213(100 \cdot 0)$ & $761(100 \cdot 0)$ & $4226(100 \cdot 0)$ \\
\hline Approval or not? & & & & & \\
Strongly approve & $94(28 \cdot 2)$ & $366(39 \cdot 8)$ & $707(31 \cdot 9)$ & $222(29 \cdot 2)$ & $1389(32 \cdot 9)$ \\
Approve & $67(20 \cdot 1)$ & $329(35 \cdot 8)$ & $709(32 \cdot 0)$ & $208(27 \cdot 3)$ & $1313(31 \cdot 1)$ \\
Do not mind & $98(29 \cdot 4)$ & $213(23 \cdot 2)$ & $747(33 \cdot 8)$ & $306(40 \cdot 2)$ & $1364(32 \cdot 3)$ \\
Disapprove & $6(1 \cdot 8)$ & $4(0 \cdot 4)$ & $22(1 \cdot 0)$ & $19(2 \cdot 5)$ & $51(1 \cdot 2)$ \\
Strongly disapprove & $1(0 \cdot 3)$ & $1(0 \cdot 1)$ & $8(0 \cdot 4)$ & $1(0 \cdot 1)$ & $11(0 \cdot 3)$ \\
Missing values & $67(20 \cdot 1)$ & $6(0 \cdot 7)$ & $20(0 \cdot 9)$ & $5(0 \cdot 7)$ & $98(2 \cdot 3)$ \\
\hline Total & $333(100 \cdot 0)$ & $919(100 \cdot 0)$ & $2213(100 \cdot 0)$ & $761(100 \cdot 0)$ & $4226(100 \cdot 0)$ \\
\hline
\end{tabular}

terms of the likelihood of a surgeon's participation; the patient recruitment rate; the patient response in terms of both rate and completeness; and, finally, in terms of cost per patient. In summary, $96 \%$ of eligible surgeons identified $89 \%$ of eligible patients, who, if still alive at three months, returned $82 \%$ of the postal questionnaires. Overall, the questionnaires lacked about $5 \%$ of the requested data.

One of the most reassuring findings was that most surgeons agreed to take part. Although peer pressure was undoubtedly influential - the national prostatectomy audit was introduced at regional audit meetings which required the presence of all surgeons and the invitation to participate was from the Royal College of Surgeons of England - this was not the only factor. The prospect of having the results of their surgical firm compared with those of their peers was, we believe, sufficient incentive. The

Table 5 Sociodemographic factors associated with missing values for different groups of questions

\begin{tabular}{|c|c|c|}
\hline \multicolumn{3}{|c|}{$\begin{array}{l}\text { Constituent questions to preoperative American Urological } \\
\text { Association symptom index score }\end{array}$} \\
\hline & $\begin{array}{l}\text { Sum of missing values } \\
\text { (mean }(95 \% \text { confidence } \\
\text { interval) })\end{array}$ & $\begin{array}{l}\text { No (\%) of } \\
\text { valid cases }\end{array}$ \\
\hline $\begin{array}{l}\text { Age by decade } \\
<61 \\
61-70 \\
71-80 \\
\geqslant 81 \\
\text { Total }\end{array}$ & $\begin{array}{l}\text { IOVA } \mathrm{F} \text { ratio }=10 \cdot 5, \mathrm{p}< \\
2 \cdot 5(2 \cdot 3 \text { to } 2 \cdot 7) \\
2 \cdot 5(2 \cdot 3 \text { to } 2 \cdot 6) \\
2 \cdot 1(2 \cdot 0 \text { to } 2 \cdot 2) \\
1 \cdot 9(1 \cdot 7 \text { to } 2 \cdot 1) \\
2 \cdot 2\end{array}$ & $\begin{array}{l}01): \\
332(9 \cdot 8) \\
1231(36 \cdot 4) \\
1344(39 \cdot 7) \\
475(14 \cdot 0) \\
3382(100 \cdot 0)\end{array}$ \\
\hline $\begin{array}{l}\text { Social class by } \\
\text { ratio }=11 \cdot 9, \\
\text { A } \\
\text { B } \\
\text { C1 } \\
\text { C2 } \\
\text { D } \\
\text { E } \\
\text { Total }\end{array}$ & $\begin{array}{l}\text { full time employment (A) } \\
\begin{array}{l}1 \cdot 8(1 \cdot 4 \text { to } 2 \cdot 1) \\
1 \cdot 9(1 \cdot 7 \text { to } 2 \cdot 0) \\
2 \cdot 1(2 \cdot 0 \text { to } 2 \cdot 2) \\
2 \cdot 4(2 \cdot 3 \text { to } 2 \cdot 6) \\
2 \cdot 7(2 \cdot 5 \text { to } 2 \cdot 9) \\
2 \cdot 6(2 \cdot 1 \text { to } 3 \cdot 0) \\
2 \cdot 2\end{array}\end{array}$ & $\begin{array}{l}\text { VA F } \\
\begin{array}{l}156(5 \cdot 0) \\
631(20 \cdot 1) \\
834(26 \cdot 6) \\
933(29 \cdot 7) \\
498(15 \cdot 9) \\
86(2 \cdot 7) \\
3138(100 \cdot 0)\end{array}\end{array}$ \\
\hline $\begin{array}{l}\text { Age of finishing } \\
\text { p }<0.001): \\
<16 \\
17-18 \\
>19 \\
\text { Total }\end{array}$ & $\begin{array}{l}1 \text { time education (ANOV } \\
\begin{array}{l}2 \cdot 3(2 \cdot 2 \text { to } 2 \cdot 4) \\
2 \cdot 1(1 \cdot 8 \text { to } 2 \cdot 2) \\
1 \cdot 8(1 \cdot 6 \text { to } 1 \cdot 9) \\
2 \cdot 2\end{array}\end{array}$ & $\begin{array}{c}\text { ratio }=11 \cdot 6, \\
2534(76 \cdot 7) \\
375(11 \cdot 3) \\
395(12 \cdot 0) \\
3304(100 \cdot 0)\end{array}$ \\
\hline $\begin{array}{l}\text { Home circumst } \\
\text { Living alone } \\
\text { Cohabiting } \\
\text { Total }\end{array}$ & $\begin{array}{l}\text { s (Independent } t \text { test, } \mathrm{p} \\
2 \cdot 2(-0 \cdot 3 \text { to } 0 \cdot 1) \\
2 \cdot 3(-0 \cdot 3 \text { to } 0 \cdot 1) \\
2 \cdot 2\end{array}$ & $\begin{array}{l}\text { 5) } \\
548(16 \cdot 4) \\
2798(83 \cdot 6) \\
3346(100 \cdot 0)\end{array}$ \\
\hline
\end{tabular}

Table 6 Notional expenditure for items attributable directly to multicentre audit

\begin{tabular}{|c|c|}
\hline Item $^{\star}$ & $\begin{array}{l}\text { Cost } \\
(£)\end{array}$ \\
\hline \multirow[t]{2}{*}{$\begin{array}{l}\text { Manpower (including oncosts): } \\
\text { Research fellow ( } 24 \text { months) } \\
1 \text { Assistant (part time) } \\
2 \text { Data collectors (12 months) } \\
\text { Hospital staff time }\end{array}$} & $\begin{array}{l}52000 \\
23000 \\
30000 \\
43000\end{array}$ \\
\hline & 148000 \\
\hline \multirow[t]{2}{*}{$\begin{array}{l}\text { Equipment: } \\
\text { Computers (including support) } \\
\text { Software } \\
\text { Optical image scanning time }\end{array}$} & $\begin{array}{l}5000 \\
2500 \\
1100 \\
\end{array}$ \\
\hline & 8600 \\
\hline \multirow[t]{2}{*}{$\begin{array}{l}\text { Stationery and printing: } \\
\text { Patient information leaflet }(10000) @ 0.06 \text { each } \\
\text { Hospital questionnaires }(7500) @ 0.35 \text { each } \\
\text { Patient questionnaire }(8000) @ 0.42 \text { each } \\
\text { Correspondence (reminders, etc) } \\
\text { Interim reports } \\
\text { Feedback report to surgeons }\end{array}$} & $\begin{array}{c}600 \\
2625 \\
3360 \\
2600 \\
1500 \\
2500\end{array}$ \\
\hline & 13185 \\
\hline \multirow[t]{2}{*}{$\begin{array}{l}\text { Postage: } \\
\text { Packs to participating centres } \\
\text { Outward mailshots } \\
\text { Prepaid returns }\end{array}$} & $\begin{array}{l}2000 \\
4000 \\
1500\end{array}$ \\
\hline & 7500 \\
\hline $\begin{array}{l}\text { Telephone calls and faxes } \\
\text { Regional meetings and travel }\end{array}$ & $\begin{array}{l}4100 \\
3500\end{array}$ \\
\hline Total & 184785 \\
\hline
\end{tabular}

*In addition $£ 26000$ was spent on flagging all recruited patients to the NHS Central Registry in Southport.

result was that participating surgeons were able to compare the outcome of their workload both with each other and against pooled data in a format analogous to a confidential comparative audit in the knowledge that like was being compared with like. ${ }^{27}$

Contrary to expectations at the start of the audit, participating surgeons identified a high proportion of patients. In the one region where this was actively pursued (South West Thames) $89 \%$ of eligible patients were identified. Although we have no way of knowing, patient recruitment may have been lower in the three other regions. In addition, it was not possible for us to be as confident about identifying accurate recruitment rates in the private sector as in the NHS. To a large extent recruitment in the private sector relied on surgeons reporting cases, whereas reporting in the NHS was invariably controlled by an independent person. Non-recruitment of eligible patients was not randomly distributed among surgeons. Most missed patients were attributable to a handful of surgeons, as most successfully recruited over $90 \%$ of eligible men.

Missing data in the hospital questionnaire were uncommon. This, together with the high rate of retrieval of hospital notes, contrasted sharply with some recent audits. ${ }^{28}$ We believe three factors were important in this regard. Firstly, the design was prospective and the questionnaires were chronological in format. Secondly, the audit involved consultants from the start. Finally, audit assistants were closely involved in checking returned questionnaires.

We have shown that high patient response rates can be achieved on a large scale, especially if patients are solicited beforehand. We have also shown that the way the study was 
conducted in the different regions was associated with different patient response rates. Regions that were administered in the same way had almost identical response rates (approximately 80\%). In contrast, South West Thames obtained a higher response rate $(87 \%)$, albeit at greater cost. This resulted from extra manpower in the form of two data collectors (only one data collector was responsible for the three remaining regions). Whether the cost required to boost the patient response rate was worth while remains unclear. The answer depends on whether the additional few percent differed systematically from the initial $80 \%$ who responded. Our analysis of late and non-response that has been published elsewhere suggests that this is not the case. ${ }^{29}$ The response rate in South West Thames was close to that achieved in other smaller studies. ${ }^{30} 31$ This supports the notion that patients are eager to be given the opportunity to report the outcome of their surgery. Having done so, few patients found the questionnaire difficult. For most variables data were available from over $95 \%$ of respondents. The only subject with a high number of missing data was sexual function in general and ejaculatory characteristics in particular.

A study designed around a reliable point of patient identification (the operating theatre), brought with it problems in recording baseline preintervention health status. Patients therefore had to be asked to recall their preoperative health status some time after their operation. The relation between such retrospective recall and contemporary accounts are reported elsewhere. ${ }^{32}$

Turning to cost estimates, we are not aware of any similar studies that have calculated cost per patient and therefore cannot compare our results with the cost of other audits. Certainly it compares favourably with pharmaceutical companies, which expect to pay investigators over $£ 500$ for identifying and completing data collection forms on one patient. In addition, as a proportion of the inhospital cost of prostatectomy (about $£ 1200$ ) the $£ 34.50$ cost per patient represents $3 \%$ of the overall cost. Whether the cost is warranted will depend on how surgeons use the audit data to modify their practice $^{33}$ and thus enhance the benefit that patients receive from their treatment.

This paper has shown that large multicentre comparative audits are feasible without increasing the cost of care by more than a few per cent. These findings need to be replicated in other areas of health care before the results can be generalised. Such information should be available soon as similar multicentre audits have been and are being conducted by the Royal College of Surgeons of England. ${ }^{34} 35$

The national prostatectomy audit was funded by a grant from the Department of Health to the Surgical Audit Unit of the Royal College of Surgeons of England

We thank Professor J P Bandy for his participation on the steering group and his editorial comments on this and other manuscripts; Carol Wood, Jackie Horrocks, and Jackie Hill for their administrative help; Philip Meredith for his comments on questionnaire design and analysis; and the following surgeons for their enthusiastic participation in the national prostatectomy audit.
NORTHERN REGION

Mr T G Armitage (South Tyneside District Hospital), Mr P M Atkinson (Darlington Memorial Hospital), Mr R G Bentley (Hexham General Hospital), Mr P J English (Dryburn Hospital), Mr J G W Feggetter (Ashington Hospital), Mr E L Gilliland (North Tees General Hospital), Mr R R Hall (Freeman Hospital), Mr J R Hindmarsh (South Cleveland (Freeman Hospital), Mr J R Hindmarsh (South Cleveland Hospital), Mr R Hole (South Cleveland Hospital), Mr F J Holmes (North Tyneside General Hospital), Mr I A Miller (Queen Elizabeth Hospital), Professor D E Neal (Freeman Hospital), Mr C Parker (Sunderland Royal Infirmary), Mr R
Pollard (North Tyneside General Hospital), Mr P H Powell Pollard (North Tyneside General Hospital), Mr P H Powell
(Freeman Hospital, Newcastle), Mr P D Ramsden (Freeman Hospital, Newcastle), Mr J R Rhind (Hartlepool General Hospital), Mr D G Richards (West Cumberland Hospital) Mr C Roberts (Bishop Auckland General Hospital), Mr R R Roy (Sunderland Royal Infirmary), Mr W G Staff (Westmorland County Hospital), Mr R W Thomson (North Tees General Hospital), Mr Renital), Mr Vadanan (Queen Elizabeth Hospital), Mr R G Willis
(Cumberland Infirmary), Ms J Whiteway (South Cleveland Hospital).

\section{WESSEX REGION}

Mr G F Abercrombie (St Mary's Hospital, Portsmouth) Mr F J Bramble (Bournemouth General Hospital), Mr C A Charlton (Royal United Hospital), Mr T J C Cooke (Salisbury General Hospital), Mr J Cumming (Southampton General Hospital), Mr P Donaldson (St Mary's Hospital, Isle of Wight), Mr M Harrison (Royal Hampshire County Hospital), Mr P J Jeffery (Weymouth and District Hospital), Mr J D Jenkins Jeffery (Weymouth and District Hospital), Mr J D Jenkins (Southampton General Hospital), Mr M G Johnson (Weymouth and District Hospital), Mr D B Mackie (Salisbury General Hospital), Mr G S McIntosh (Salisbury General
Hospital), Mr D Meikle (Weymouth and District Hospital), Hospital), Mr D Meikle (Weymouth and District Hospital),
Mr C U Moisey (Royal United Hospital, Bath), Mr B Morgans Mr C U Moisey (Royal United Hospital, Bath), Mr B Morgans
(Princess Alexandra Hospital), Mr J Iacovou (Princess Margaret Hospital, Swindon), Mr A B Richards (Basingstok District Hospital), Mr J S Rundle (Bournemouth) General Hospital), Mr C J Smart (Southampton General Hospital) Mr B H Walmsley (St Mary's Hospital, Portsmouth), Mr Vinnicombe (St Mary's Hospital, Portsmouth), Mr T Walsh (St Mary's Hospital, Isle of Wight).

MERSEY REGION

Mr T Brightmore (Chester Royal Infirmary), Mr R Crosbie (Arrowe Park Hospital, Upton), Mr A Desmond (Broadgreen Hospital Trust, Liverpool), Mr J Elkington (Arrowe Park Hospital, Upton), Mr M Fordham (Broadgreen Hospital Trust Liverpool), Mr G Foster (Chester Royal Infirmary), Mr M Hea (Leighton Hospital Trust, Crewe), Mr Holden (Macclesfield District General Hospital), Mr J Kane (Chester Royal Infirmary), Mr W Lloyd-Jones (Broadgreen Hospital Trust, Liverpol), Mr D Machin (Fazakerley Hospital, Liverpool), Mr J Mey (Whis Mool),

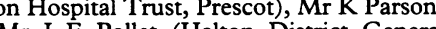
(Royal Liverpool), Mr J E Pollet (Halton District General Hospital), Mr C Powell (Leighton Hospital Trust, Crewe), Mr J Shennan (Arrowe Park Hospital, Upton), Mr K Soin (Walton Hospital, Liverpool), Mr M Williamson (Fazakerley Hospital, Liverpool), Mr S Vesey (Southport and Formby District General Hospital), Mr K Woolfenden (Royal Liverpoo University Hospital), Mr A Wu (Walton Hospital, Liverpool), Mr R Ewing (Halton District General Hospital).

TRENT REGION

Validation study: Mr J K Wightman, Miss R Styles (Chesterfield Royal Hospital).

SOUTH WEST THAMES REGION

Mr E C Ashby (Royal West Sussex Hospital, Chichester), Mr M J Bailey (Epsom Hospital), Mr R C Beard (Worthin Hospital), Mr P J R Boyd (St Helier Hospital, Carshalton) Mr P Britton (Royal West Sussex Hospital, Chichester), Mr Bull (Crawley Hospital), Mr C R Charig (Epsom Hospital), Mr R S Cole (St Peter's Hospital, Chertsey), Mr J Davenport (St Peter's Hospital, Chertsey), Mr G Das (Mayday Hospital, Ellis (Ashford Hospital), Mr S Ghazali (Queen Mary's Elis (Ashford Hospital), Mr S Ghazali (Queen Mary's Hospital, Roehampton), Mr E Gordon (St George's Hospital, Hopkins (Crawley Hospital), Mr M C Jennings (East Surrey Carshalton), Mr M Lavelle (Princess Royal Hospital, Haywards Heath), Mr J Maynard (Princess Royal Hospital, Haywards Heath), Mr R G Notley (Royal Surrey Hospital), Mr E Palfrey (Frimley Park Hospital), Mr D C Parr (Worthing Hospital), Mr T G Rao (St Peter's Hospital, Chertsey), Mr P Riddle (Parkside Hospital, Wimbledon), Mr Rogers (New Victoria Royal Hospital, Haywards Heath), Mr F A W Schweitzer (Royal Surrey Hospital, Guildford), Mr R A P Scott (Royal (Royal Surrey Hospital, Guildford), Mr R A P Scott (Royal West Sussex Hospital, Chichester), $\mathrm{Mr} R$ D C Southcott (Mayday Hospital, Thornton Heath), Mr B Ujam (Mayday Hospital, Thornton Heath), Mr C Jondon), Mr Yates-Bell (Ashstead Hospital).

We also thank the following people for acting as local coordinators during the study.

NORTHERN REGION

Ms Suzanne Gower (South Tyneside District Hospital), Ms Catherine Elcoat (Darlington Memorial Hospital), Ms Julie Middleton, Ms Samantha Harrison (Hexham General Hospital), Ms Anne Sewell (Dryburn Hospital), Ms Jane 
Reynolds (Freeman Hospital, Newcastle), Ms Ann O'Kane, Ms Anne Wallace (Ashington Hospital), Amanda McGough, Ms Maureen Lonsdale (North Tees General Hospital), Ms Jennifer Donoghue (South Cleveland Hospital), Ms Joyce Hayes (North Tyneside General Hospital), Ms Pauline Blakey (Ques (Nlizath Hospital), Karen Ramsey (Sunderland Boy Queen Elizabeth Hospital), Karen Ramsey (Sunderland Royal Infirmary), Ms Joyce Roycroft (North Tyneside General Hospital), Ms Beryl Percival, Ms Christine Evans (Hartlepool General Hospital), Ms Carol Elliott (West Cumberland Hospital), Mr Phillip Whitfield (Bishop Auckland General Hospital), Ms Pam Hackney (Westmorland County Hospital), Ms Karen Brown (Furness General Hospital), Mr Ralph Messersmith (Cumberland Infirmary)

WLSSI: REGIO.

Ms Jane Dawson, Mr Steve Chiverton (St Mary's Hospital, Portsmouth), Ms Karen Hatchard (Bournemouth General Hospital), Ms Audrey Beaver (Royal United Hospital, Bath), Ms Virginia Taylor, Ms Hilary Mace (Salisbury General Hospital), Ms Sue Lydeard (Southampton University Hospitals NHS Trust), Ms Julie Allsop (St Mary's Hospital, Isle of Wight), Ms Angela Flavell (Royal Hampshire County Hospital, Winchester), Ms Cecilia Wiseman (Southampton General Hospital), Weymouth and District Medical Audit Department, ward clerks and secretaries, Mrs Shepardson (Princess ward clerks and secretaries, Mrs Shepardson (Princess Alexandra Hospital), Ms Jenny Rendell, Ms Hilda Cooper
(Princess Margaret Hospital), Ms Valerie Sloat (Basingstoke District Hospital)

ML:RSEYY REGION

Mr Bancroft Grasey (Chester Royal Infirmary), Ms Diane Williams (Arrowe Park Hospital, Upton), Mr D Irvine, Ms Lynn Preece (Broadgreen Hospital Trust, Liverpool), Ms Judith Newell (Leighton Hospital Trust), Ms Susan Hughes (Macclesfield District General Hospital), Ms Sandra Corfe, $\mathrm{Mr}$ Stephen Mangen (Fazakerley Hospital, Liverpool), Ms Sandra Bryan, Ms Stephanie Arno (Whiston Hospital Trust, Prescot), Ms Sue Horton (Roval Liverpool University Hospital), Mrs Ruth Cooney (Halton District Gencral Hospital), Mrs A M General Ms Jill Kirk (Southport and Formby District General Hospital).

SOCHH WEST THA.MISS REG GIO.

Mrs Anne Fish and Mrs Margaret Pyle (Roval Surrey County Hospital, Guildford). Validation study addressing capture rates.

Mr Andy Challands, Ms Joan Smith (Chesterfield Royal Mr Andy Challands, Ms Joan Smith (Chesterfield Royal
Hospital). Validation study addressing contemporaneous versus recollected symptom capture.

1 Graversen P, Gasser T, Wasson J, Hinman F, Bruskewitz R. Controversies about indications for transurethral resection of the prostate. F Urol 1989;141:475-81.

2 Barry M, Mulley A, Fowler F, Wennberg J. Watchful waiting is. immediate transurethral resection for symptomatic
prostatism. The importance of patient preferences. $7 A M A$ prostatism. The importar
$1988 ; 259(20): 3010-7$

3 Roos NP, Wennberg JE, Malenka DJ, Fisher ES, McPherson K, Andersen TF, et al. Mortality and reoperation after open and transurethral resection of the prostate for benign prostatic hypertrophy. ${ }^{\circ} \mathrm{Engl} \mathcal{F} \mathrm{Mcd}$ 1989;320:1120-4.

4 Wolverson R, Blacklock A, Geddes J, O'Hagan A. Factors influencing post-operative hospital stay after transurethral resection of the prostate gland Br f Urol 1986;58:161-3.

5 Sage W, Kessler R, Sommers L, Silverman J. Physician generated cost containment in transurethral prostatectomy. F Urol 1988;140:311-5.

6 Litwin M, Kahn K, Reccius N. Why do sicker patients cost more? A charged base analysis of patients undergoing prostatectomy. F Urol 1993;149:84-8.

7 So E, Ho P, Bodenstab W, Parsons C. Erectile impotence associated with transurethral prostatectomy. Lrologv' 1982;19:259-62

8 Bolt J, Evans C, Marshall V. Sexual dysfunction after prostatectomy. Br F Urol 1986;58:319-22.

9 Chassin MR, Brook RH, Park RE, Kessey J, Fink A Kosecoff $\mathrm{J}$, ot al. Variations in the use of medical and surgical services by the medicare population. N Engl 7 Med 1986;314:285-90.

0 McPherson K, Wennberg J, Hovind O, Clifford P. Smallarea variations in the use of common surgical procedures: an international comparison of New England, Fingland and Norway. N Engl f Med 1982;307:1310.

11 Wennberg J. The paradox of appropriate care. 7.1.1A 1987;258:2568-9.

12 Barry $M$. Epidemiology and natural history of benign prostatic hyperplasia. Urol Clin North Am 1990;17:195.

13 Neal D, Ramsden P, Sharples L. Outcome of elective prostatectomy. BMf 1989;229:762

14 O'Leary M, Barry M, Fowler F. Hard measures of subjective outcomes: validating symptom indexes in urology. $7 A M A$ 1992;148:1546-8

15 Doll H, Black N, McPherson K, Flood A, Williams ( Smith J. Mortality, morbidity, and complications following transurethral resection of the prostate for benign ing transurethral resection of the prostate for

16 Krumins P, Fihn S, Kent D. Symptom severity and patients values in the decision to perform a transurethral resection of the prostate. Med Dicis Making 1988;8:1-8.

17 Malone P, Edmonson R, Gill M, Shearer R. Prostatectoms; patients' perceptions and long term follow up. Br. F C rol 1988;61:234-8.

18 Emberton M, Rivett R, Ellis B. Comparative audit a new method of audit delivers. Ann $R$ Coll Surg lingl $1991 ; 73$ (suppl 6):117-20.

19 Brook R. Maintaining hospital quality: the need for international cooperation. $\mathcal{F} A M A$ 1993;270:985-7.

20 Black N A, Moore L. Comparative audit between hospitals: the example of appendicectomy. International foumal of Ouality Assurance in Health Care 1994;7:11-15.

21 Emberton M. Meredith P. Caught in the act? Automated data entry for the purposes of clinical audit. British Fommal of Health Care Computing 1993;10(9):32-4

2 Emberton M, Rockall T, Meredith P. Evaluation of an integrated questionnaire design and automated data entry system in a clinical audit unit. British foumal of Health Care Computing 1994;11(5):23-5.

23 Barry M, Fowler F, O'Leary $\mathrm{M}$, ot al. The American Urological Association's symptom index for benign prostatic hyperplasia. 7 Crol 1992;148:15.49-57.

24 Barry MJ, Fowler FJ, O'Leary MP, Bruskewit\% RC, Holtgreve HL, Mebust WK, et al. Correlation of the AUA symptom index with self administered versions of the Madsen-Iverson, Bovarsky, and Maine medical assessment programme sumptom indexes. F [ rol 1092: assessment prog

25 Stewart A, Hays R, Ware J. The MOS short form health survey: reliability and validity in a patient population. Med Care 1988;26:724.

26 Fowler F, Wennberg J, Timothy R, Barry M, Mulley A, Hanley D. Symptom status and quality of life following prostatectomy. FAMA 1988;259:3018 22

27 Emberton $\mathrm{M}$, Black $\mathrm{N}$. The impact of late response and non-response in a multi-regional surgical outcome audit International foumal for Quality in Health Care 1995 ; $7(1): 47-55$.

28 Emberton M. The national prostatectomv andit: a compuratici audit for participating surgeons. I ondon: Roval College of Surgeons of England 1094

29 Vickers N, Pollock A. Incompleteness and retrieval of case notes in a case note audit of colorectal cancer. Quality in Health Care 1993;2:170-4.

30 Ware J, Havs R. Methods of measuring patient satisfaction with specific medical encounters. Med Care 1988;26:393.

31 Wilson R, Macintvre I. Symptomatic outcome after laparoscopic cholecystectomy Br. F Surg 1993;80 $439 \cdots 41$.

32 Emberton M, Challands A, Styles R, Wightman J, Black X. Recollected versus contemporary patient reports of preoperative svmptoms in men undergoing transurethral operative symptoms in men undergoing transurethral
prostatectomy for benign disease. 7 Clin Epidicmiol prostatectomy for

33 Emberton M, Neal DE, Black N, Harrison M, Fordham M, McBrien MP, et al. The National Prostatectomy Audit: the clinical management of patients during hospital admission. Br f Crol 1995; 75:301-16.

34 Rockall TA, Logan RFA, Devlin HB, Northfield TC. Incidence and mortality from acute upper gastrointestinal haemorrhage in the UK. Gut 1994;35(suppl 5):S47.

35 O'Riordan D. National groin hernia outcomes project. London: Royal College of Surgeons of England, 1995 